\title{
IN MEMORIUM OF B. “IRV” SUMMERS
}

As a journal editor, it is sometimes a sad duty to notify readers of the passing of a fellow scholar and colleague who in their lifetime made significant contribution to the growth of that journal. Such is the case with the passing of "Irv" Summers. Irv earned his Ph.D. in 1971 from Wayne State University and held teaching positions at Avila University, Indiana State University, Missouri State University, and Wayne State University. I first met Irv and his lovely wife and fellow scholar, Sharon, at an academic conference in Prague in the year 2000, and through the following years I would look forward to conversing with Irv at the Academy, at IBAM, or various international conferences. Upon becoming Associate Editor of JBAM, I was delighted to find Irv serving as a trusted reviewer and member of the Editorial Board.

Irv's service to JBAM was immeasurable. When JBAM needed a quick turn around on a review of a manuscript or when JBAM needed a third review to break a deadlock regarding the merit of a particular manuscript, Irv was always available. His reviews were thoughtful, well referenced, scholarly in tone, and highly beneficial to the authors, regardless of the recommendation to accept, revise and resubmit, or reject. As an editor, one could only wish for a "stable" of reviewers with Irv's sense of dedication and professionalism. The work of many authors appearing in JBAM was unknowingly enhanced because of Irv's tireless efforts. Finally, sorely missed most of all in the coming years will be Irv's sage advice to the Editors of JBAM.

Ernie Stark, Editor. 